\title{
30 years on from the molecular cloning of interferon-tau
}

\author{
R Michael Roberts \\ University of Missouri-Columbia - Animal Sciences, 240B Bond Life Sciences Center, Columbia, Missouri, USA \\ Correspondence should be addressed to M R Roberts; Email: robertsrm@missouri.edu
}

Reproduction (2017) 154 E1-E2

November 26, 2017, marks the 30th anniversary of the publication of a paper that demonstrated that a protein implicated in maternal recognition of pregnancy in sheep was an interferon (Imakawa et al. 1987), which eventually became known as interferon-tau (IFNT). Earlier this year, Kevin Sinclair, Editor-in-Chief for Reproduction, and Ramiro Alberio, the Review Editor, indicated that they would like to publish a special issue of Reproduction to commemorate this event. They invited me to act as a Guest Editor in recruiting 4-5 review articles that described how this field of research developed and how it has evolved since that 1987 publication. I contacted five pairs of individuals, and, thankfully, all agreed to submit manuscripts and to meet a fairly short deadline.

I first asked my previous colleagues at the University of Florida, Fuller Bazer and Bill Thatcher, to chronicle the studies that led up to the discovery and characterization of IFNT. It is important to stress that the 'discovery' did not just begin with the cloning of the IFNT transcript, but had its origins over the previous two decades. In particular, the identification of IFNT is grounded in the landmark experiments of Moore and Rowson in the 1960s that led to the inference that the active factor was most likely a protein secreted by the conceptus for only a narrow window of time during the preimplantation phase of conceptus development. Bazer and Thatcher also provide a general overview of how the field has progressed over the past 30 years and their view of where it might be going next (Bazer \& Thatcher 2017).

The second contribution is from Tom Spencer and Tod Hansen, who are both well known for their work on the downstream effects of IFNT. I asked them to discuss the paracrine actions of IFNT on the maternal uterine epithelium and how it blocks the luteolytic action of PGF2 $\alpha$. However, ever since it was first observed that early pregnant ewes had elevated levels of circulating interferon (Schalue-Francis et al. 1991), there has been a realization that IFNT likely has endocrine actions in addition to its local effects on the uterus. The endocrine aspect of IFNT action, also described in the Spencer/ Hansen review, has also raised the possibility that the detection of either IFNT or IFN-inducible proteins in the blood might form the basis of an early pregnancy test in cattle (Hansen et al. 2017).

I have long believed that the key to understanding much the biology of IFNT lies in explaining its expression pattern, especially its unique localization to trophectoderm and its massive production over only a few days of pregnancy. In addition, I have long been skeptical of the idea that IFNT has special properties that distinguishes it from related IFN such as IFN $\alpha$ (IFNA) and IFN $\omega$ (IFNW). Instead, I came to the conclusion that the uniqueness of the IFNT system is in the highly conserved transcriptional control regions of its genes, which lack the virally inducible features of other type I IFN. Accordingly, I asked two pioneers in the IFNT field, Toshihiko Ezashi and Kazuhiko Imakawa to review what is currently known about the controls operating over transcription of IFNT in trophoblast (Ezashi \& Imakawa 2017). Dr Imakawa was, of course, the first author on the 1987 Nature paper, while Dr Ezashi had described the ETS2/AP1/DLX3 enhancer element crucial in regulating IFNT gene expression (Roberts et al. 2003).

A second aspect of the IFNT that has long intrigued me is how this gene family evolved and came to be represented in the Ruminantia sub-order and in no other mammalian taxon. Species within this suborder possess a unique synepitheliochorial placenta, which is essentially non-invasive and a derived form of placentation (Wildman et al. 2006). Importantly, the divergence of the IFNT from its common IFNW ancestor occurred approximately 36 million years ago, roughly coinciding with the time that the pecoran ruminants emerged from the main Artiodactyla lineage. The linkage between the IFNT and the ruminant-type of placentation provides an example illustrating that the nature of the biochemical communication possible between conceptus and mother must change as the characteristics of the maternal-fetal interface itself evolves. I asked Alan 
Ealy and his student Lydia Woolridge (Ealy \& Woolridge 2017) to tackle this intriguing topic.

The final review by Niamh Forde and Pat Lonergan deals with the link between IFNT and fertility (Forde \& Lonergan 2017). Although there remains little doubt that IFNT is the primary agent in signaling maternal recognition of pregnancy and that it protects the corpus luteum of pregnancy from the luteolytic action of PGF2 $\alpha$, pregnancies can still fail even after a conceptus has developed to a stage when it is releasing IFNT. Moreover, pregnancy losses in cattle and sheep and, by analogy, other ruminants are relatively high during this critical period and a cause of serious financial loss to producers. Forde and Lonergan address the important issue of early pregnancy failure and its links to IFNT production by the conceptus. Among the questions raised are whether or not this infertility is the result of insufficient production of IFNT by the conceptus, the inability of the maternal uterus to respond appropriately to IFNT or a lack of appropriate synchrony between the conceptus and an endometrium under the primary influence of progesterone.

A brief video introducing a compendium of the five reviews, celebrating the 30th anniversary of the November 26, 1987 Nature paper, describing the molecular cloning from sheep embryos of what was then known as ovine trophoblast protein-1 and now as interferon-tau is also available (Video 1).

\section{Video 1}

Interferon-tau and me: a personal recollection. View video from the online version of the article available at http://dx.doi.org/10.1530/REP-17-0585.

Until the 'discovery' of IFNT, it remained unclear how, in domestic ruminant species, a conceptus made its presence known to the mother and, in particular, prevented regression of the corpus luteum and a return to estrous cyclicity. In fact, not a great deal was known about this crucial aspect of pregnancy in any mammal, with the possible exception of primates where chorionic gonadotrophins had been implicated in luteal maintenance. In cattle sheep and goats, the question was not just academic but one of practical and economic importance to animal agriculture. There was also the presumption that, whatever differences existed across mammals in the manner that the conceptus implants and in the morphologies of their placentae, common mechanisms for luteal rescue might exist across phyla. They clearly do not. The identification of IFNT and ability to produce it in recombinant form led to an upsurge in studies on in vitro cell models and whole animals, such that we now know more about the mechanism of maternal recognition of pregnancy in cattle and sheep than in any other species, including the human and mouse. The work led to the shared award of the Wolf Prize in Agriculture, which some regard as the agricultural 'Nobel', to Fuller Bazer and $m e$ in 2002/2003 (https://nihrecord.nih.gov/ newsletters/03_04_2003/story07.htm) and provided the foundation of a career for many of the trainees we mentored. Although I am reluctant to predict where the field is going, what is certain is that, like the original discovery, it will be driven by new technologies, such as the CRISPR/Cas9 gene editing system now readily applied to large animal models, and by adequate funding from government agencies. I, for one, am deeply grateful to the Reproductive Sciences Branch of the Eunice Shriver National Institute of Child Health and Human Development, NIH, and my Program Officer Dr Koji Yoshinaga who were bold enough to provide over 25 years of support for a project on sheep. I also wish to thank the many individuals who worked as technicians, graduate students and postdoctoral fellows in my laboratory during my time at the University of Florida (1970-1985) and the University of Missouri (1986-present). I am especially grateful to two individuals, Drs Toshihiko Ezashi and Andrei Alexenko, who have looked after me over the past 20 years.

\section{References}

Bazer FW and Thatcher WW 2017 Chronicling the discovery of interferon tau. Reproduction 154 F11-F20. (doi:10.1530/REP-17-0257)

Ealy AD and Wooldridge LK 2017 The evolution of interferon-tau. Reproduction 154 F1-F10. (doi:10.1530/REP-17-0292)

Ezashi T and Imakawa K 2017 Transcriptional control of IFNT expression. Reproduction 154 F21-F31. (doi:10.1530/REP-17-0330)

Forde N and Lonergan P 2017 Interferon-tau and fertility in ruminants. Reproduction 154 F33-F43. (doi:10.1530/REP-17-0432)

Hansen TR, Sinedino LDP \& Spencer TE 2017 Paracrine and endocrine actions of interferon tau (IFNT). Reproduction 154 F45-F59. (doi:10.1530/REP-17-0315)

Imakawa K, Anthony RV, Kazemi M, Marotti KR, Polites HG \& Roberts RM 1987 Interferon-like sequence of ovine trophoblast protein secreted by embryonic trophectoderm. Nature 330 377-379. (doi:10.1038/330377a0)

Roberts RM, Ezashi T, Rosenfeld CS, Ealy AD \& Kubisch HM 2003 Evolution of the interferon tau genes and their promoters, and maternaltrophoblast interactions in control of their expression. Reproduction Supplement $61239-251$.

Schalue-Francis, TK, Farin PW, Cross JC, Keisler D \& Roberts RM 1991 Effect of injected bovine interferon-alpha I1 on estrous cycle length and pregnancy success in sheep. Journal of Reproduction and Fertility 91 347-356. (doi:10.1530/jrf.0.0910347)

Wildman, DE, Chen C, Erez O, Grossman LI, Goodman M \& Romero R 2006 Evolution of the mammalian placenta revealed by phylogenetic analysis. PNAS 103 3203-3208. (doi:10.1073/pnas.0511344103)

Received 22 September 2017

Accepted 6 October 2017 